\title{
Numerical model of tracked vehicle crossing inland water
}

\author{
Mariusz Pawlak ${ }^{*}$, Sebastian Sławski ${ }^{1}$, and Stawomir Duda ${ }^{1}$ \\ ${ }^{1}$ Silesian University of Technology, Institute of Theoretical and Applied Mechanics, \\ Konarskiego 18a., 44-100 Gliwice
}

\begin{abstract}
In this paper, a numerical model of tracked vehicle with a simplified suspension and a winch forcing movement at a constant speed of $2 \mathrm{~m} / \mathrm{s}$ is presented. The simplified vehicle body was created in the CAD environment, the suspension model, dry and wet obstacle, as well as the winch system and material models, were created in the LS PREPOST. The body of the vehicle was treated as a rigid, mounted by springs and dampers on tracks, the solid element was replaced by a shell element with assigned moments of inertia and mass in the node located in the centre of gravity of the vehicle. The characteristics of the resultant contact force of vehicle travel on the rigid ground for a dry and water obstacle are presented.
\end{abstract}

\section{Introduction}

In the case of tracked vehicles, especially military ones, there is a need to cross terrain obstacles, for example, ditches, river beds, both dry and filled with water. In the case of a water obstacle, there is a risk of losing the vehicle's contact with the ground, which may cause a loss of control over the vehicle by the flow of the river. To be able to carry out the analysis of passing the tracked vehicle, a vehicle model with a modelled suspension, a definition of contact between the tracks and the ground, and modelling of motion are needed. For this purpose, the article presents a model with a simplified suspension and a winch forcing movement at a constant speed of $2 \mathrm{~m} / \mathrm{s}$. The LS DYNA software is an environment that enables the modelling of a vehicle suspension, with a forced movement of a rigid body as well as the modelling of the fluid-structure interaction. The simplified vehicle body was created in the CAD environment, the suspension model, dry and wet obstacle, as well as the winch system and material models, were created in the LS PREPOST. Because the body of the vehicle can be treated as a rigid, mounted by springs and silencers on tracks, the question was whether the solid element could be replaced by a shell element with assigned moments of inertia and mass in the node located in the centre of gravity of the vehicle. The characteristics of the resultant contact force of vehicle travel on the rigid ground for a dry and water obstacle will be presented.

\footnotetext{
* Corresponding author: mariusz.pawlak@polsl.pl
} 


\section{Comparison of the shell and solid model in the numerical buoyancy analysis}

To compare the solid model with the shell model were created three cuboids with the same moments of inertia and mass. The models are presented in table 1. For calculation the following input data was adopted: length $=5 \mathrm{~m}$ along $X$-axis, width $=4 \mathrm{~m}$ along the $Z$ axis and height $=3 \mathrm{~m}$ along $Y$ axis. Assuming that density of water is $\rho_{w}=1000 \mathrm{~kg} / \mathrm{m}^{3}$, analysed object is heavier than water and with an averaged density of the solid $\rho_{b}=1000 \mathrm{~kg} / \mathrm{m}^{3}$, the total mass of solid will be $m=\rho_{b} \cdot V \mathrm{~kg}=72000 \mathrm{~kg}$. Moments of inertia in centre of gravity of a cuboid are as follow:

$$
I_{l}=1 / 12 \cdot m\left(w^{2}+h^{2}\right) \quad I_{w}=1 / 12 \cdot m\left(l^{2}+h^{2}\right) \quad I_{h}=1 / 12 \cdot m\left(l^{2}+w^{2}\right)
$$

For the coordinate system applied in model moment are as follow:

$$
I_{x}=150000 \mathrm{~kg} \cdot \mathrm{m}^{2} \quad I_{y}=246000 \mathrm{~kg} \cdot \mathrm{m}^{2} \quad I_{z}=204000 \mathrm{~kg} \cdot \mathrm{m}^{2}
$$

Is assumed that centre of gravity is in the centroid of the cuboid (material is homogeneous) $X c=3.5 \mathrm{~m}, Y c=2 \mathrm{~m}, Z c=1.8 \mathrm{~m}$.

Table 1. Models description.

\begin{tabular}{|c|c|c|}
\hline $\begin{array}{c}\text { Model_1 } \\
\text { Cuboid as solid body } \\
\text { (l)5mx(h)3mx(w) } 4 \mathrm{~m}\end{array}$ & $\begin{array}{c}\text { Model_2 } \\
\text { Cuboid as solid body with } \\
\text { Part_Inertia }\end{array}$ & $\begin{array}{c}\text { Model_3 } \\
\text { Cuboid as a surface body with } \\
\text { part inertia }\end{array}$ \\
\hline $\begin{array}{c}126102 \text { nodes, } 60000 \text { solids as } \\
\text { rigid elements }\end{array}$ & $\begin{array}{c}126103 \text { nodes, } 6000 \text { solids as } \\
\text { rigid elements, } \\
\text { constrained } \\
\text { extranodes_node }\end{array}$ & $\begin{array}{c}70684 \text { nodes, } 9400 \text { shells as } \\
\text { rigid elements } \\
1 \text { constrained } \\
\text { extrannodes_node }\end{array}$ \\
\hline
\end{tabular}

From the dynamic equation of translational motion

$$
F=m \cdot a
$$

Where mass is $48000 \mathrm{~kg}$, and force $F$ is the vector sum of the weight of the object and the buoyancy of the water.

$$
\begin{gathered}
F=F_{c}+F_{w} \\
F_{c}=\mathrm{m} \cdot \mathrm{g} \\
F_{w}=\rho_{\text {water }} \cdot g \cdot V
\end{gathered}
$$

Forces in applied model are as follow:

$$
F_{c}=709920 \mathrm{~N} \quad F_{w}=588360 \mathrm{~N} \quad F=121560 \mathrm{~N}
$$

Based on the difference in the density of water and solid, can be determined the acceleration of the falling of the body in the water:

$$
a=g \cdot\left(1-\rho_{\text {water }} / \rho_{b}\right)
$$

Assuming the initial velocity $V_{0}=0 \mathrm{~m} / \mathrm{s}$, the path $s_{0}=0$ from the uniform motion equation $s=a t^{2} / 2$ and the acceleration of the body in the water $1.634 \mathrm{~m} / \mathrm{s}^{2}$, is determined the maximum falling time of the cuboid $t=2.47 \mathrm{~s}$. There are many publications describing drop tests of bodies of various shapes into the water [6-12], and in derived theoretical 
models the resistance force resulting from the shape and the type of surface of the object is added to the buoyancy force. Based on those forces the resistance factors are calculated. In the presented drop tests were compared kinematic quantities to determine whether the model simplification by adopting only the outer layer of the coating with the assigned moments and the mass in the centre of gravity by part inertia command in LS Dyna will be sufficient. The characteristics of the drop test in the water for all three variants are presented. In the system is taken into account gravitational acceleration $g=9.806 \mathrm{~m} / \mathrm{s}^{2}$ parallel to the y-axis. Contact between the bottom plate located above the water border and the rectangular prism was established. Prepared model and hydrostatic pressure distribution were shown on Fig. 1.

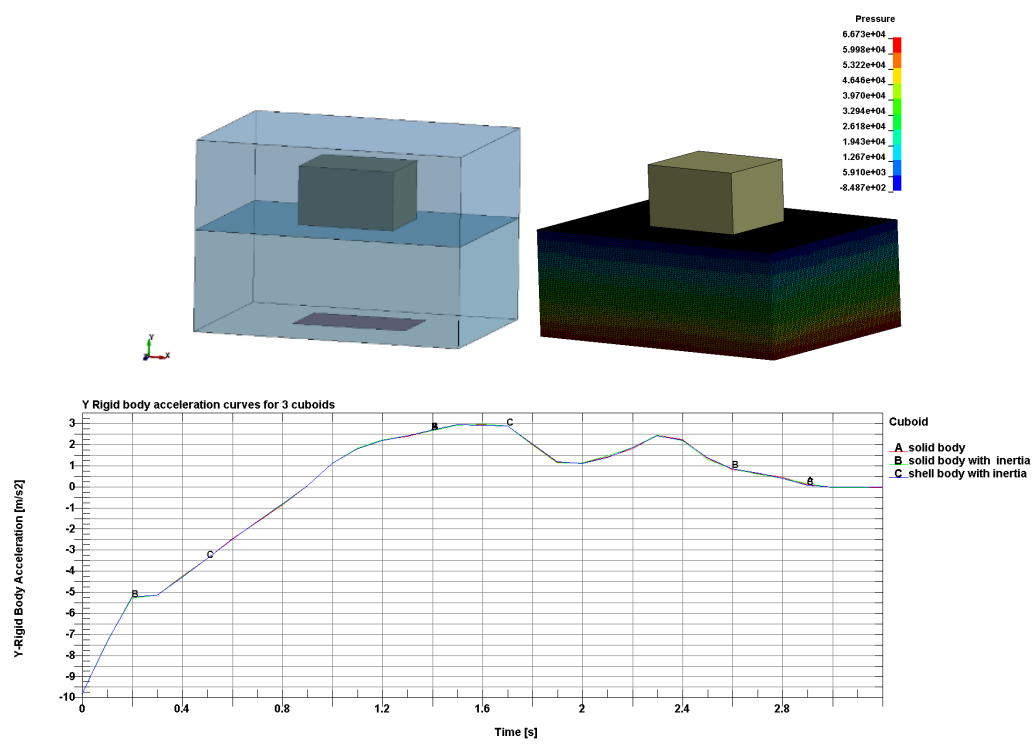

Fig. 1. Hydrostatic pressure distribution in the water and $\mathrm{Y}$ axis rigid body acceleration $\mathrm{A})$ rigid solid body B)rigid solid body with mass and inertia assigned in the node located in gravity centre C)rigid shell body with mass and inertia assigned in the node located in gravity centre.

As can be noticed there is no difference in rigid body acceleration for all three cuboids, the difference between analytical calculation and numerical results of max. Acceleration is because the centre of the rigid body initially was in the air and initial acceleration was $9.806 \mathrm{~m} / \mathrm{s} 2$ what resulted in the slightly larger time of drop test. Due to the size of the analysed system, the volume of water and air was discretized using the finite element method with regular cubic elements with a size of $0.1 \mathrm{~m}$. The ALE grid is the same in the whole system, consisting of 1409860 nodes, 137200 solid deformable elements. An atmospheric pressure of 101,300 $\mathrm{Pa}$ has been set for the air, which can be seen in the form of pressure on the water surface. Along with depth, the value of hydrostatic pressure is increasing. The pictures below (Fig. 2) show the steps of immersing the object in water in chronological order.

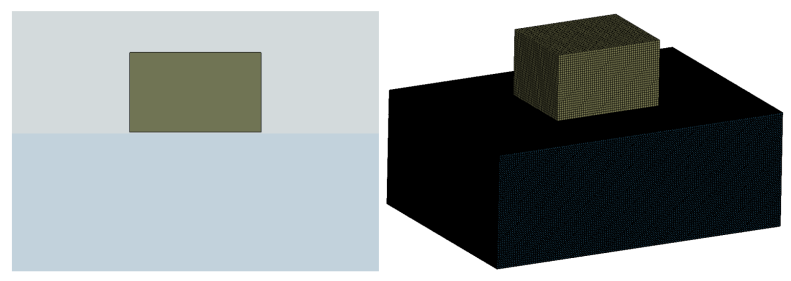




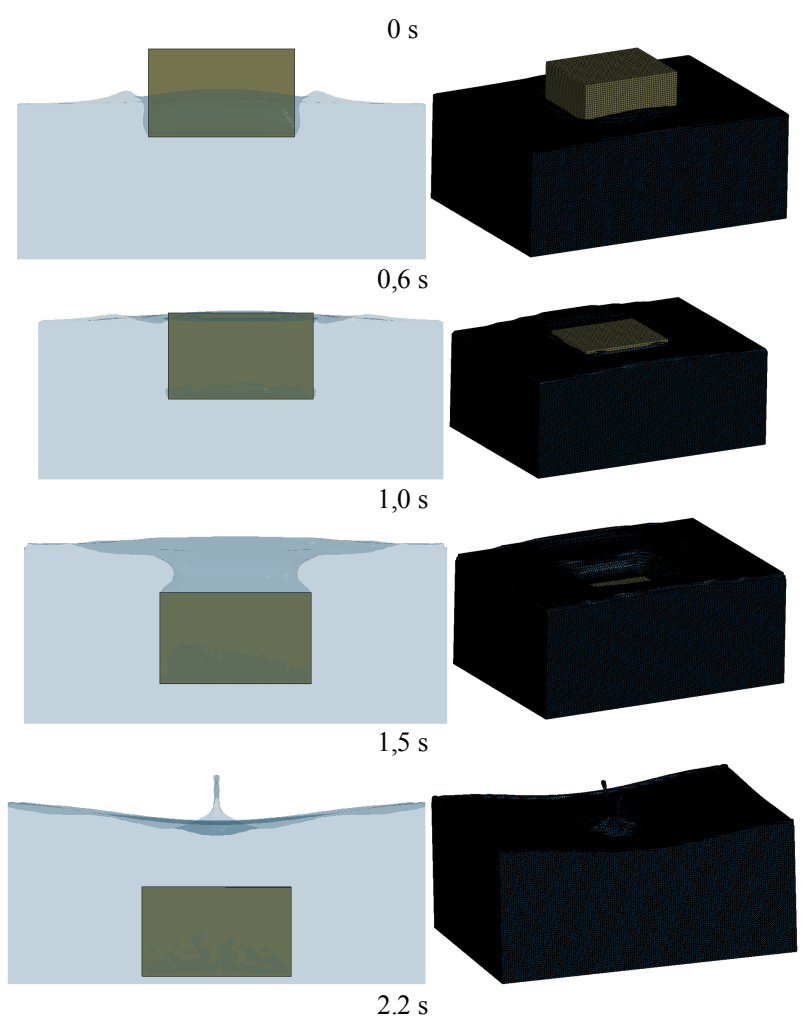

Fig. 2. Numerical results from Cuboid drop test in a function of time.

During the experimental drop test of cuboid into the water (Fig. 3), a higher amount of air bubbles trapped in the water was observed.
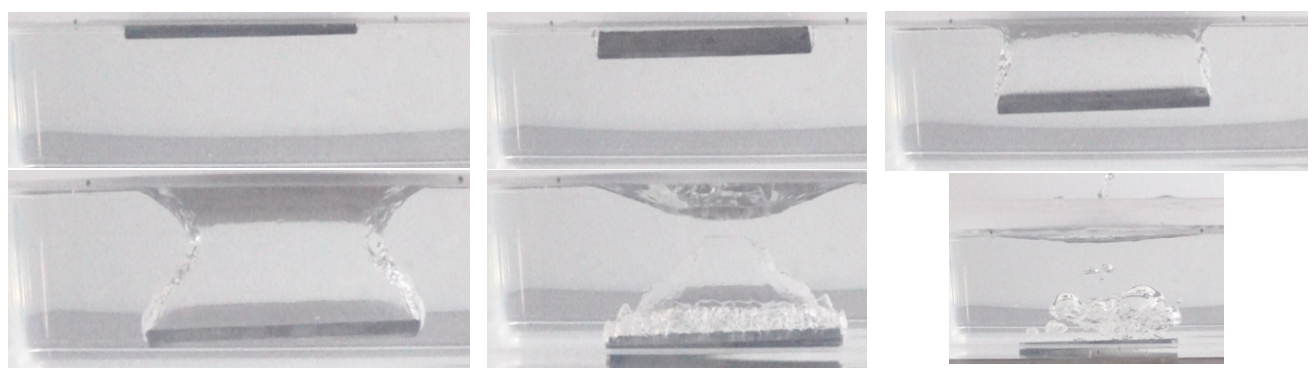

Fig. 3. Sample images from the real drop test of cuboid

Analysing the characteristics presented in Fig.1 can be noticed the compatibility between models. Due to the significant reduction in the number of finite elements in the model no. 3 and a significant reduction in simulation time, this method will be applied to the vehicle model with suspension.

\section{The numerical model of the tracked vehicle}

To analyse the dynamics of the tracked vehicle crossing through the water obstacle, the LS DYNA computing environment was selected. It is a software package for the analysis of fast-changing phenomena using the explicit finite element method to calculate engineering 
problems. The calculation system consists of a vehicle model with assigned mass moments of inertia, springs, dampers and tracks that simulate caterpillar tracks. As the first, analysis of dropping the rectangular prism from the height just above the water level to the bottom of the $5 \mathrm{~m}$ deep reservoir was carried out. It was necessary to investigate whether there is a difference between a rigid solid model and a rigid shell model with assigned moments of inertia and mass in the node. The number of finite elements was significantly reduced due to the use of the rigid method and the shell model. The second test was the simulation of passing through a dry obstacle and the results presented in Chapter 4 This is due to the necessity of checking whether the object moves with a constant maximum linear speed of $2 \mathrm{~m} / \mathrm{s}$ to avoid a greater dynamic pressure distribution during fluctuating acceleration and deceleration in water. The next stage was the creation of a water environment using elements of ALE (Euler Lagrange Equations) used in modelling strongly non-linear phenomena, such as, for example, explosions in air and water. Due to the large size of the facility, along with the obstacle, there were restrictions on the minimum finite element sizes, for which the computing power of the computer will be sufficient. Simulations were carried out in the LS DYNA 9.0 environment. The CAD model from the Autodesk Inventor environment in *.step format was imported into the LS Prepost software, moved along the $\mathrm{x}$ and y-axes to obtain the coordinate system's compatibility with the one shown in Fig. 2 and Fig. 4 (in the next stage of calculations). The position of the model on the Z-axis was not changed because the system was symmetrical. The units in which the model is created in Autodesk Inventor are $\mathrm{kg}$ and $\mathrm{mm}$, hence the need for conversion to the SI system. The vehicle has been simplified to form one solid.

The vehicle model was discretized using the finite element method in the LS Prepost / LS Dyna environment. Two types of models were prepared, a solid model and a shell model to further compare the results. The solid model consists of tetrahedral elements (tetra), in the shell model triangular elements $2 \mathrm{~d}$ were used. Because in the buoyancy problem there were not interesting stress values in the model, only interaction with the fluid/structure, the vehicle was modelled as a rigid body.

In the case of modelling solids as a rigid body with overwritten mass and moments of inertia, density, Young's modulus and Poisson's number play a secondary role. The *MAT_NULL model of the material was assumed for air and water. In table 2 materials properties are presented (in SI units).

Table 2. Air and water material parameters in SI units.

\begin{tabular}{|c|c|c|c|}
\hline \multicolumn{4}{|l|}{ Air } \\
\hline MID & RO & $\mathrm{PC}$ & MU \\
\hline 3 & 1.252 & -10 & $1.846 \mathrm{E}-05$ \\
\hline \multicolumn{4}{|l|}{ water } \\
\hline MID & RO & $\mathrm{PC}$ & $\mathrm{MU}$ \\
\hline 1 & 1000 & $-1.000 \mathrm{E}+04$ & $8.684 \mathrm{E}-04$ \\
\hline
\end{tabular}

For ALE elements with *mat_null are necessary equations of state (EOS), the simplest is linear polynomial. Equations of state for air and water are presented in table 3.

Table 3. Air and water Equation of state parameters.

\begin{tabular}{|c|c|c|c|c|}
\hline \multicolumn{5}{|c|}{ *EOS LINEAR POLYNOMIAL } \\
\hline EOSID & $\mathrm{C} 4$ & $\mathrm{C} 5$ & E0 & V0 \\
\hline air & 0.4 & 0.4 & $2.533 \mathrm{E}+05$ & 1.0 \\
\hline EOSID & $\mathrm{C} 0$ & $\mathrm{C} 1$ & E0 & V0 \\
\hline water 4 & $1.013 \mathrm{E}+05$ & $2.250 \mathrm{E}+09$ & 0.0 & 0.0 \\
\hline
\end{tabular}


The model created in LS Prepost /LS Dyna consists of 147928 shell elements, 74060 nodes and 29 discrete elements - 15 springs and 14 dampers. These elements are described using the Lagrange method used in classical computer stereomechanical and dynamic mechanical analyses. Stiffness of springs was taken from the literature [2]. 3400000 solid elements forming air and water are described by the ALE method, which allows the transfer of pressures between elements of fluid mechanics and solid state mechanics. Interaction between Lagrange and ALE elements was implemented by *Constrained_lagrange_in_solid, friction between water and cuboid was set to 0. The volume of the vehicle was modelled as a surface rigid body (the distance between any points does not change) for which properties of mass and mass moments of inertia were determined by * PART_INERTIA. Fig. 4 presents the discrete model of the vehicle with given moments of inertia.

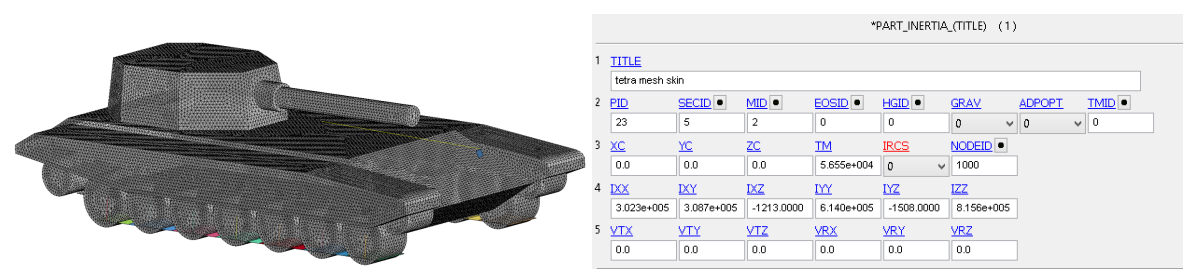

Fig. 4. The model of the vehicle along with the assigned centre of mass and moments of inertia

In node no. 1000 located in the middle of the vehicle mass, the body of the rigid moment of inertia in units of $\mathrm{kg} \cdot \mathrm{m}^{2}$ and mass $56550 \mathrm{~kg}$, was assigned. Below is a view of Springspecific discrete elements with a defined stiffness and dampers with a given damping coefficient. Thanks to this the vehicle could freely cross the obstacle on numerical simulations. A rigid body with given displacements along axes $X, Y$ and $Z$ connected to the vehicle through a discrete element spring with higher stiffness simulates a winch with a velocity equal to $2 \mathrm{~m} / \mathrm{s}$ in accordance with design requirements.

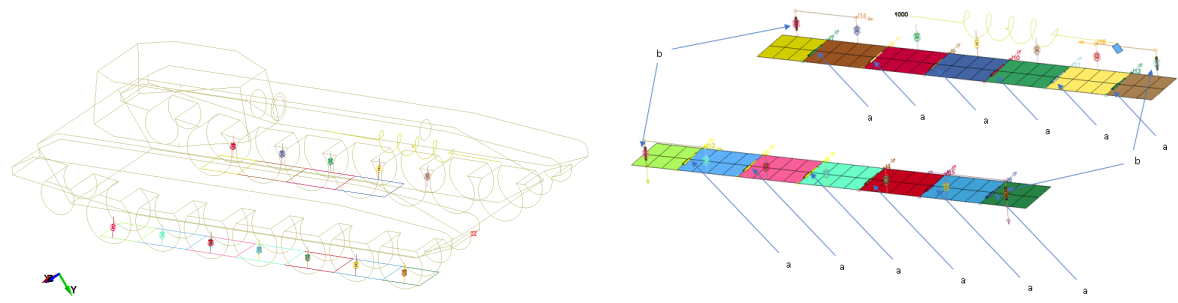

Fig. 5. The view of shell elements being simplified track drive of the vehicle, by the letter a are marked rotational joints, by the letter $\mathrm{b}$ are marked translational joints.

\section{Tracked vehicle crossing dry obstacle}

In crossing dry obstacle there is no need to have ALE elements, and the simulations were very fast. Below (Fig. 6) is presented model with dry obstacle and resultant contact force between track and ground. 


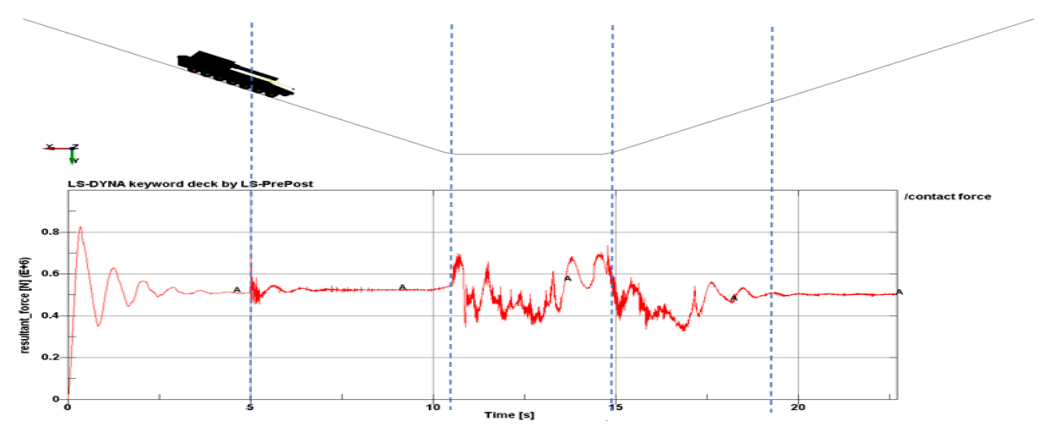

Fig. 6. Resultant total contact force distribution in a function of time, dry obstacle.

It is noticeable that the value of the contact force will stabilize before $5 \mathrm{~s}$., after which the small fluctuation takes place when the object starts to move, and the total contact force is again stabilized up to 10.5 second. After this time, the vehicle descends from a plane inclined at an angle of 30 degrees to the level and goes to the straight. At this moment, the resultant value of the contact force for a short while increases and after this is decreasing to the lowest value. This takes place despite the lack of influence of hydrostatic pressure on the water. After $15.1 \mathrm{~s}$ the vehicle goes uphill on an inclined plane inclined at an angle of 30 degrees to the level, which gives value fluctuations and stabilization after $19 \mathrm{~s}$.

\section{Tracked vehicle crossing water obstacle}

It is noticeable that the value of the contact force will stabilize before 5 seconds, after which the object starts to move, and the small fluctuation of the value is visible. In $10 \mathrm{~s}$. is noticeable stabilization. The value of the resultant force is smaller because the buoyancy force appears. After this time, the vehicle descends from a plane inclined at an angle of 30 degrees to the level and goes to the straight. At this point, the resultant value of the contact force decreases to the minimum value. The influence of water buoyancy is visible. Before 15 seconds, the vehicle enters a plane inclined at an angle of 30 degrees to the level, which gives value fluctuations and stabilization after 19 seconds. The value of the contact force distribution depending on time was shown in Fig. 7.
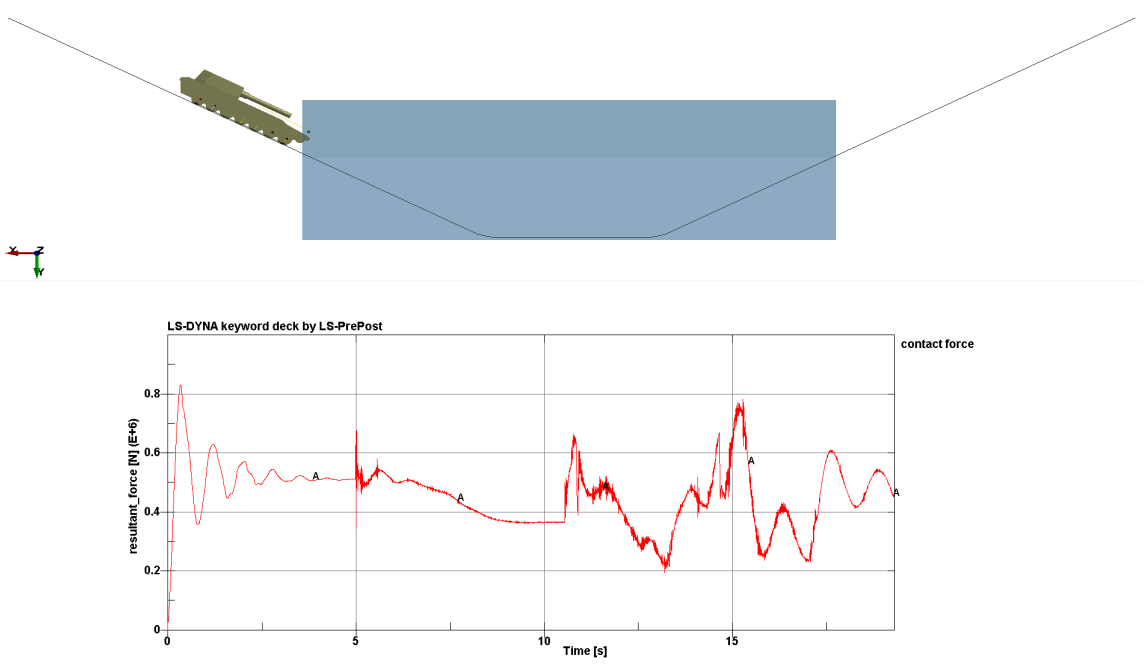

Fig. 7. Resultant total contact force distribution in a function of time, water obstacle. 


\section{Conclusion}

LS DYNA solver was chosen for analysis of the water influence on the tracked vehicle during passing through water obstacle. The body of the vehicle was treated as a rigid body mounted by springs and dampers on tracks, and the Vehicle model was created with by shell elements with assigned moments of inertia and mass in the node, located in the centre of gravity of the vehicle. The characteristics of the resultant contact force of vehicle travel on the rigid ground for a dry obstacle and an obstacle water filled was presented and the influence of buoyancy was noticed.

\section{REFERENCES}

1. M. Souli, A. Ouahsine, L. Lewin. ALE formulation for fluid-structure interaction problems. Computer methods in applied mechanics and engineering, 190, 659-675, (2000)

2. J. Gniłka, A. Mężyk. Experimental identification and selection of dynamic properties of a high-speed tracked vehicle suspension system. Exploatacja i Niezawodność Maintenance and Reliability, 19 (1): 108-113, (2017)

3. L. Olovsson, M. Souli, I. Do. LS-DYNA -ALE capabilities (Arbitrary-LagrangianEulerian) Fluid-Structure Interaction Modeling, Livermore Software Technology Corporation, (2003)

4. Guenter, H. Hohl, Military terrain vehicles, Journal of Terramechanics, Vol. 44, Is. 1, (2007)

5. Helvacioglu, S., et al., Improving the river crossing capability of an amphibious vehicle, Ocean Engineering, Vol. 38, Is. 17-18, 2011.

6. Krueger B., Wirtz S., Scherer V., Measurement of drag coefficients of non-spherical particles with a camera-based method, Powder Technology, vol 278, 157-170, (2015)

7. Xianzhi S., Zhengming X., Gensheng L., Zhaoyu P., Zhaopeng Zhu, A new model for predicting drag coefficient and settling velocity of spherical and non-spherical particle in Newtonian fluid, Powder Technology 321, 242-250, (2017)

8. Nakisa M., Maimun A., Ahmed Y.M., Behrouzi F., Tarmizi A., Numerical estimationof shallow water effect on multipurpose amphibious vehicle resistance, Journal of Naval Architecture and Marine Engineering, 14, 1-8, (2017)

9. Vassilakos G.J., Elemental Water Impact Test: Phase 120 -inch Hemisphere, NASA/CR2015-218679

10. Kotowski M., Barnat W., Experimental and numerical buouyancy analysis of tracked military vehicle, Journal of Kones Powertrain and Transoprt, Vol. 19, No. 4 (2012)

11. Chengzhong H., Wei B., Study on water entry problem using a level-set immersed boundary method, 5th International Symposium on Physics of Fluids, International Journal of Modern Physics: Conference Series, Vol. 34, 1460376-11 pages, (2014)

12. J. Mohd-Yusof, Combined immersed boundary/B-spline method for simulations of flows in complex geometries, in Center Annual Research Briefs, NASA Ames/Stanford University, p. 317 (1997) 